\title{
MANIPULATING CYTOCHROME P450 ENZYMES: NEW PERSPECTIVES FOR CANCER TREATMENT
}

\author{
Stanislav Yanev* and Tsveta Stoyanova \\ Department of Drug Toxicology, Institute of Neurobiology, Bulgarian Academy of Sciences, Sofia, Bulgaria
}

\begin{abstract}
Increasing drug efficiency and reducing drug overall toxicity are two of the main goals of today's drug chemotherapy of cancer. In general this could be achieved by searching new ways for selective active drug accumulation in cancer cells by manipulating local drug metabolism or delivery. In this short review, on the basis of the main directions described by McFadyen et al. (Mol Cancer Ther 2004; 3(3): 363-371), new data is reported for localization and expression of cytochrome P450 enzymes in human tumors, development of cytochrome P450-based and gene-directed enzyme activated prodrugs, antisense-based P450 and immune-based therapy, cytochrome P450 polymorphism in development of anticancer drugs. New discoveries of molecular biology of cancer give us hope for more successful development of modern cancer chemotherapy. Biomed Rev 2017; 28: 120-124.
\end{abstract}

Keywords: cytochrome P450 isoforms, cancer cells, drug metabolism, drug delivery

\section{INTRODUCTION}

The cytochrome P450 superfamily of hemoproteins are involved in the oxidative metabolism of a wide range of toxic foreign compounds and have a central role in influencing the response of established tumors to anticancer drugs; these enzymes can either activate or deactivate many anticancer drugs. The outcome, in terms of drug activation (i.e., results in cytotoxicity) or deactivation (i.e. no cytotoxicity and potentially resistance), is dependent upon the relative amount and activity of specific CYPs in individual tumor cells. The achievements of the various "omics" scientific trends enable us more successfully to increase efficiency and reduce the toxicity of anticancer agents by selective manipulation of the expression and activity of different cytochrome P450s in tumor cells (2).

\section{Localization and Expression of Cytochrome P450 Enzymes in Human Tumors}

A recent comprehensive overview showed expression of practically all the cytochrome P450 superfamily in human bronchial and peripheral lung tissue with high inter-individual variety of expression in non-small lung cancer cells which in turn could explained the different individual susceptibility towards the deleterious effects of inhaled chemical toxicants and carcinogens (3). A well-known fact is the presence of metabolically active $C Y P 1 B 1$ in $70 \%$ of renal cell carcinomas with no CYP1B1 activity in normal kidneys (4). Over expression of CYP1B1 and other CYP's isoforms were found also in tumors of the lung, breast, liver, gastrointestinal tract, prostate and bladder which turns it into a crucial factor in cancerogenesis as well as in an important target for successful anticancer therapy (5-11). This makes CYP1B1 an earlystage tumor marker (12). CYP2W1 has also been identified as having tumor-specific expression in colon and adrenal cancer (13) and the extent of this expression could serve as an independent prognostic factor for overall survival (14). Elevated CYP1A1 expression was shown in human bladder cancer relative to normal human tissues (15). CYP2J2 was found to be overexpressed in adenocarcinoma and breast carcinoma as well as in hematopoietic system malignant cells (16).

* Correspondence and reprint request to Dr Stanislav Yanev, Department of Drug Toxicology, Institute of Neurobiology, Bulgarian Academy of Sciences, 1113 Sofia, Bulgaria

E-mail: stanislav_yanev@yahoo.com 
Table 1. Cytochrome P450' isoforms specific metabolism of different anticancer drugs

\begin{tabular}{|c|c|c|c|}
\hline Cytochrome P450's & Drugs & Deactivation & Activation \\
\hline CYP1A2 & Dacarbazine & no & yes \\
\hline CYP2A6 & Ftorafur, Tegafur & no & yes \\
\hline \multirow{2}{*}{ CYP2B } & Altretamine & yes & no \\
\hline & Cyclophosphamide, Ifosfamide, Procarbazine, Thiotepa & no & yes \\
\hline CYP2C & Bexarotene, Paclitaxel, Tretinoin & yes & no \\
\hline \multirow{2}{*}{ CYP2D6 } & Doxorubicin & yes & - \\
\hline & Idarubicin & no & yes \\
\hline \multirow[t]{2}{*}{ CYP3A4 } & $\begin{array}{l}\text { Busulfan,Cytarabine, Gefitinib, Irinotecan, Teniposide, } \\
\text { Topotecan, Vinblastine, Paclitaxel }\end{array}$ & yes & no \\
\hline & Ifosfamide, Ellipticine, MMDX & no & yes \\
\hline
\end{tabular}

CYP4Z1 is overexpressed in breast carcinoma (3). All recent data showed that the CYP expression profile in an individual tumour is likely to be an important determinant in predicting the outcome of cancer chemotherapy (17).

\section{Anticancer Drugs Metabolized by Cytochrome P450 Enzymes}

Several anticancer agents are metabolized by one or more cytochrome P450s with two different outcomes of the corresponding metabolites: deactivation or activation $(18,19)$ (Table 1). A specific CYP450 Reductase-mediated doxorubicin reduction under anaerobic conditions was found. formation. Phortress is active against ovarian, breast and colorectal cancer (22-24).

- Aminoflavone exerts Phortress-like cytotoxic action after CYP 1A1 and 1A2 induction (2).

- DUM-135 is activated by CYP1B1 to form its active metabolite, DMU-117 (a tyrosine kinase inhibitor) (2).

- Methoxymorpholinyl doxorubicin (MMDX) is a novel prodrug activated by human CYP3A4 to a potent long-lived and cell-permeable cytotoxic metabolite (25).

- Resveratrol is activated by CYP1B1 to an active metabolite Piceatannol, a tyrosine kinase inhibitor with antileukaemic activity (scheme 1) $(26,27)$.

\section{Development of Cytochrome P450- Based Activated Prodrugs}

The specific preferential expression of different cytochrome P450 isoforms in human tumor cells allows the synthesis of selectively activated prodrugs (20), like:

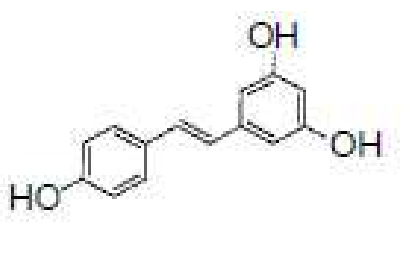

Resveratrol
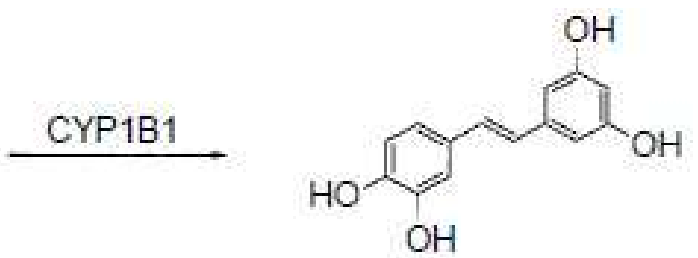

Piceatannol
- Anticancer nitric oxide donors - aryl oximes, N-nitrosamines, N-hydroxyguanidines (21).

- Phortress (dihydrochloride salt of 2-(4-amino-3-methyl 2-(4-amino-3-methyl-phenyl)-5-fluorobenzothiazole selectively) after sequestration only in benzothiazole sensitive (MCF-7 breast) cells and binding to cytosolic aryl hydrocarbon receptor ( $\mathrm{AhR})$, proceeds with translocation of the complex to the cell nucleus where the consistent activation of CYP1A1 gene transcription leads to subsequent induction of CYP1A1-catalyzed metabolism of Phortress to reactive electrophilic species and results in DNA-adduct
- Pro-drug analogs of duocarmycin were activated by CYP1B1 (7).

\section{Bioreductive Anticancer Drugs}

Hypoxic tumors have very poor prognosis and do not respond to existing chemotherapy thus requiring another therapeutic approach - bioreductive drug activation. The principle of bioreductive drug activation is that in the reductive environment created by hypoxia, endogenous reductases will transfer electrons to a nontoxic prodrug to generate a 
reduced cytotoxic metabolite (28). Hence, this provides for differential killing of hypoxic tumors versus normal tissues. Here are some typical examples:

- mitomycin C (19).

- aromatic and heterocyclic nitro compounds (RSU1069, CB1954, pimonidazole) (29).

- aliphatic $N$-oxides: AQ4N (Novacea) is activated by CYP3A4 only under hypoxic conditions to form the active topoisomerase inhibitor AQ4 (30).

- benzotriazine di- $N$-oxides derivatives (tirapazamine) (31).

- Recent experiments showed that combining selective downregulation of cytochrome $\mathrm{P} 450$ reductase with newly synthesized tubulysin analog conjugated to 2-nitroimidazole (code name KEMTUB012-NI2) shows higher efficacy (1000 times more potent than tirapazamine) toward hypoxic tumor cells with limited systemic toxicity (31).

\section{Gene Therapy: Targeting Drug and Enzyme to the Tumor}

Confers on tumor cells the genetic capacity to activate a prodrug locally, within the tumor, and is designed to increase antitumor activity while minimizing toxic side effects to critical host tissues (32).

- Intratumoral injection of plasmid DNA, or retrovirus encoding P450.

- Localized delivery of P450-expressing cells encapsulated in cellulose sulphate.

- Use of human macrophages transduced with a hypoxiaregulated $\mathrm{P} 450$ cDNA.

- Intratumoral delivery of conditionally replicating oncolytic herpes virus encoding P450.

- Hypoxia-targeted gene therapy using an adenovirus that expresses P450R specifically under hypoxic conditions.

- Cyclophosphamide: a prodrug-activating P450 (CYP 2B6) gene is delivered to the tumor cell using a suitable gene therapy vector, providing for localized, intratumoral prodrug activation and enhanced tumor cell killing (29).

Cytochrome P450 Enzymes as a Mechanism of Drug Resistance

Increased expression of CYP1B1 in patients with ovarian cancers leads to the development of drug resistance to anticancer drugs which are inactivated metabolically by CYP1B1. Such drugs are docetaxel, doxorubicin, paclitaxel (in treatment of ovarian cancer (33)), mitoxantrone and tamoxifen.

\section{Small Molecule Inhibitors of Cytochrome P450s}

The use of specific low-molecular-weight chemical inhibitors of CYP1B1 to modulate the cytotoxic profile of some anticancer drugs is still under experimental stage. Examples: a methylated derivative of oxyresveratrol (piceatannol); tetramethyl stilbene; O-demethylation of biochanin A (a principle isoflavonoid found in red clover) by CYP1B1 produce genistein which in turns inhibited the enzyme. Another contemporary approach to enhance efficacy and reduce toxicity of anticancer drugs is their simultaneous delivery with some micellar cytochrome P450 inhibitors such as the well-known CYP3A4 inhibitor natural furanocoumarin 6',7'-dihydroxybergamottin (DHB). Intravenous application of DHB-micelles and docetaxel markedly increased antitumor efficacy in mice xenografted with MDA-MB-231 cells and showed enhanced plasma stability avoiding the reticuloendothelial system accumulation (34).

\section{Antisense-Based P450 Therapy}

Further options for inhibiting the metabolism of anticancer drugs at their target site and in this way increasing their clinical efficacy are the antisense-based CYP strategies by suppressing or preventing CYP1B1 expression at the site of the tumor (1).

\section{Immune-Based Therapy}

ZYC300 is a CYP1B1-based DNA vaccine, designed to stimulate the immune system against tumor cells expressing CYP1B1 (7).

\section{Influence of Cytochrome P450 Polymorphisms on Drug Development and Anticancer Therapy}

Defining the profile of the individual tumors and identifying those CYPs that are overexpressed is of great importance to the successful future development of new anticancer drugs $(35,36)$. At the same time no less important for the clinician is to have clear cut information on the patient's cytochrome P450 phenotype, lowering in this way the inter-patient variability, minimizing side-effects and maximizing therapeutic efficacy (37-39). The advent of novel technologies such as tissue microarrays and protein chips should facilitate the potential of tailoring patient-specific therapeutic regimens based on individual CYP expression in tumor cells.

\section{CONFLICT OF INTEREST STATEMENT}

The authors declare that the research was conducted in the absence of any commercial or financial relationships that could be construed as a potential conflict of interest. 


\section{REFERENCES}

1. McFadyen MC, Melvin WT, Murray GI. Cytochrome P450 enzymes: novel options for cancer therapeutics. Mol Cancer Ther 2004; 3(3): 363-371.

2. Bruno RD, Njar VC. Targeting cytochrome P450 enzymes: a new approach in anti-cancer drug development. Bioorg Med Chem 2007; 15(15): 5047-5060. [DOI: 10.1016/j.bmc.2007.05.046]

3. Leclerc J, Tournel G, Courcot-Ngoubo Ngangue E, Pottier N, Lafitte J-J, Jaillard S, Mensier E, et al. Profiling gene expression of whole cytochrome P450 superfamily in human bronchial and peripheral lung tissues: Differential expression in non-small cell lung cancers. Biochimie 2010; 92(3): 292-306. [DOI: 10.1016/j.biochi.2009.12.007]

4. McFadyen MC, Melvin WT, Murray GI. Cytochrome P450 CYP1B1 activity in renal cell carcinoma. $\mathrm{Br}$ $J$ Cancer 2004; 91(5): 966-971. [DOI: 10.1038/ sj.bjc.6602053]

5. Saini S, Hirata H, Majid S, Dahiya R. Functional significance of cytochrome P450 1B1 in endometrial carcinogenesis. Cancer Res 2009; 69(17): 7038-7045. [DOI: 10.1158/0008-5472.CAN-09-1691]

6. Karlgren M, Gomez A, Stark K, Svard J, RodriguezAntona C, Oliw E, Bernal ML, et al. Tumor-specific expression of the novel cytochrome P450 enzyme, CYP2W1. Biochem Biophys Res Commun 2006; 341(2): 451-458. [DOI: 10.1016/j.bbrc.2005.12.200]

7. McFadyen MC, Murray GI. Cytochrome P450 1B1: a novel anticancer therapeutic target. Future Oncol 2005; 1(2): 259-263. [DOI: 10.1517/14796694.1.2.259]

8. Oyama T, Kagawa N, Kunugita N, Kitagawa K, Ogawa M, Yamaguchi T, Suzuki R, et al. Expression of cytochrome P450 in tumor tissues and its association with cancer development. Front Biosci 2004; 9(1967-1976. [DOI: $10.2741 / 1378$ ]

9. Tokizane T, Shiina H, Igawa M, Enokida H, Urakami S, Kawakami T, Ogishima T, et al. Cytochrome P450 1B1 is overexpressed and regulated by hypomethylation in prostate cancer. Clin Cancer Res 2005; 11(16): 5793-5801. [DOI: 10.1158/1078-0432.CCR-04-2545]

10. Wen X, Walle T. Cytochrome P450 1B1, a novel chemopreventive target for benzo[ $\alpha]$ pyrene-initiated human esophageal cancer. Cancer Letters 2007; 246(1): 109-114. [DOI: 10.1016/j.canlet.2006.02.003]

11. D’Uva G, Baci D, Albini A, Noonan DM. Cancer chemo- prevention revisited: Cytochrome P450 family 1B1 as a target in the tumor and the microenvironment. Cancer Treatment Reviews 2018; 63(Supplement C): 1-18. [DOI: 10.1016/j.ctrv.2017.10.013]

12. Murray GI, Patimalla S, Stewart KN, Miller ID, Heys SD. Profiling the expression of cytochrome P450 in breast cancer. Histopathology 2010; 57(2): 202-211. [DOI: 10.1111/j.1365-2559.2010.03606.x]

13. Gomez A, Karlgren M, Edler D, Bernal ML, Mkrtchian $\mathrm{S}$, Ingelman-Sundberg $\mathrm{M}$. Expression of CYP2W1 in colon tumors: regulation by gene methylation. Pharmacogenomics 2007; 8(10): 1315-1325. [DOI: 10.2217/14622416.8.10.1315]

14. Edler D, Stenstedt K, Ohrling K, Hallstrom M, Karlgren $\mathrm{M}$, Ingelman-Sundberg M, Ragnhammar P. The expression of the novel CYP2W1 enzyme is an independent prognostic factor in colorectal cancer - a pilot study. Eur J Cancer 2009; 45(4): 705-712. [DOI: 10.1016/j. ejca.2008.11.031]

15. Sutherland M, Gill JH, Loadman PM, Laye JP, Sheldrake HM, Illingworth NA, Alandas MN, et al. Antitumor Activity of a Duocarmycin Analogue Rationalized to Be Metabolically Activated by Cytochrome P450 1A1 in Human Transitional Cell Carcinoma of the Bladder. Molecular Cancer Therapeutics 2013; 12(1): 27-37. [DOI: 10.1158/1535-7163.mct-12-0405]

16. Chen C, Wei X, Rao X, Wu J, Yang S, Chen F, Ma D, et al. Cytochrome P450 2J2 Is Highly Expressed in Hematologic Malignant Diseases and Promotes Tumor Cell Growth. Journal of Pharmacology and Experimental Therapeutics 2011; 336(2): 344-355. [DOI: 10.1124/ jpet.110.174805]

17. Lane CS, Nisar S, Griffiths WJ, Fuller BJ, Davidson BR, Hewes J, Welham KJ, et al. Identification of cytochrome P450 enzymes in human colorectal metastases and the surrounding liver: a proteomic approach. Eur $J$ Cancer 2004; 40(14): 2127-2134. [DOI: 10.1016/j. ejca.2004.04.029]

18. Kivisto KT, Kroemer HK, Eichelbaum M. The role of human cytochrome P450 enzymes in the metabolism of anticancer agents: implications for drug interactions. $\mathrm{Br}$ J Clin Pharmacol 1995; 40(6): 523-530. [DOI: 10.1111/ j.1365-2125.1995.tb05796.x]

19. Rooseboom M, Commandeur JN, Vermeulen NP. Enzyme-catalyzed activation of anticancer prodrugs. Pharmacol Rev 2004; 56(1): 53-102. [DOI: 10.1124/ pr.56.1.3] 
20. Ortiz de Montellano PR. Cytochrome P450-activated prodrugs. Future Medicinal Chemistry 2013; 5(2): 213228. [DOI: 10.4155/fmc.12.197]

21. Cai TB, Wang PG. Recent developments in anticancer nitric oxide donors. Expert Opinion on Therapeutic Patents 2004; 14(6): 849-857. [DOI: 10.1517/13543776.14.6.849]

22. Leong CO, Suggitt M, Swaine DJ, Bibby MC, Stevens MF, Bradshaw TD. In vitro, in vivo, and in silico analyses of the antitumor activity of 2-(4-amino-3-methylphenyl)5-fluorobenzothiazoles. Mol Cancer Ther 2004; 3(12): $1565-1575$.

23. Loaiza-Pérez AI, Trapani V, Hose C, Singh SS, Trepel JB, Stevens MFG, Bradshaw TD, et al. Aryl Hydrocarbon Receptor Mediates Sensitivity of MCF-7 Breast Cancer Cells to Antitumor Agent 2-(4-Amino-3-methylphenyl) Benzothiazole. Molecular Pharmacology 2002; 61(1): 13-19. [DOI: 10.1124/mol.61.1.13]

24. Mukherjee A, Martin SG. In vitro cytotoxicity of Phortress against colorectal cancer. Int J Oncol 2006; 29(5): 1287-1294. [DOI: 10.3892/ijo.29.5.1287 ]

25. Lu H, Waxman DJ. Antitumor activity of methoxymorpholinyl doxorubicin: potentiation by cytochrome P450 3A metabolism. Mol Pharmacol 2005; 67(1): 212-219. [DOI: 10.1124/mol.104.005371]

26. Potter GA, Patterson LH, Wanogho E, Perry PJ, Butler PC, Ijaz T, Ruparelia KC, et al. The cancer preventative agent resveratrol is converted to the anticancer agent piceatannol by the cytochrome P450 enzyme CYP1B1. Br J Cancer 2002; 86(5): 774-778. [DOI: 10.1038/ sj.bjc.6600197]

27. Wolter F, Clausnitzer A, Akoglu B, Stein J. Piceatannol, a natural analog of resveratrol, inhibits progression through the $\mathrm{S}$ phase of the cell cycle in colorectal cancer cell lines. J Nutr 2002; 132(2): 298-302.

28. Wilson WR, Hay MP. Targeting hypoxia in cancer therapy. Nat Rev Cancer 2011; 11(6): 393-410. [DOI: 10.1038/ nrc3064]

29. Riddick DS, Lee C, Ramji S, Chinje EC, Cowen RL, Williams KJ, Patterson AV, et al. Cancer chemotherapy and drug metabolism. Drug Metab Dispos 2005; 33(8): 1083-1096. [DOI: 10.1124/dmd.105.004374]

30. McCarthy HO, Yakkundi A, McErlane V, Hughes CM,
Keilty G, Murray M, Patterson LH, et al. Bioreductive GDEPT using cytochrome P450 3A4 in combination with AQ4N. Cancer Gene Therapy 2002; 10(40. [DOI: 10.1038/sj.cgt.7700522]

31. Lazzari P, Spiga M, Sani M, Zanda M, Fleming IN. KEMTUB012-NI2, a novel potent tubulysin analog that selectively targets hypoxic cancer cells and is potentiated by cytochrome p450 reductase downregulation. Hypoxia 2017; 5(45-59. [DOI: 10.2147/HP.S132832]

32. Zhang J, Kale V, Chen M. Gene-Directed Enzyme Prodrug Therapy. The AAPS Journal 2015; 17(1): 102110. [DOI: 10.1208/s12248-014-9675-7]

33. Zhu Z, Mu Y, Qi C, Wang J, Xi G, Guo J, Mi R, et al. CYP1B1 enhances the resistance of epithelial ovarian cancer cells to paclitaxel in vivo and in vitro. Int J Mol Med 2015; 35(2): 340-348. [DOI: 10.3892/ijmm.2014.2041]

34. Paolini M, Poul L, Darmon A, Germain M, Pottier A, Levy L, Vibert E. A new opportunity for nanomedicines: Micellar cytochrome P450 inhibitors to improve drug efficacy in a cancer therapy model. Nanomedicine: Nanotechnology, Biology and Medicine 2017; 13(5): 1715-1723. [DOI: 10.1016/j.nano.2017.03.006]

35. Rodriguez-Antona C, Gomez A, Karlgren M, Sim SC, Ingelman-Sundberg M. Molecular genetics and epigenetics of the cytochrome P450 gene family and its relevance for cancer risk and treatment. Human Genetics 2010; 127(1): 1-17. [DOI: 10.1007/s00439-009-0748-0]

36. Purnapatre K, Khattar SK, Saini KS. Cytochrome P450s in the development of target-based anticancer drugs. Cancer Lett 2008; 259(1): 1-15. [DOI: 10.1016/j.canlet.2007.10.024]

37. Mathijssen RH, van Schaik RH. Genotyping and phenotyping cytochrome P450: perspectives for cancer treatment. Eur J Cancer 2006; 42(2): 141-148. [DOI: 10.1016/j.ejca.2005.08.035]

38. Rodriguez-Antona $\mathrm{C}$, Ingelman-Sundberg M. Cytochrome P450 pharmacogenetics and cancer. Oncogene 2006; 25(11): 1679-1691. [DOI: 10.1038/sj.onc.1209377]

39. Scripture CD, Sparreboom A, Figg WD. Modulation of cytochrome $\mathrm{P} 450$ activity: implications for cancer therapy. Lancet Oncol 2005; 6(10): 780-789. [DOI: 10.1016/ S1470-2045(05)70388-0] 